\title{
Produção, acúmulo e decomposição da serapilheira em uma restinga da Ilha do Mel, Paranaguá, PR, Brasil ${ }^{1}$
}

\author{
Luciana A. Pires ${ }^{2,5}$, Ricardo Miranda de Britez ${ }^{3}$, Guy Martel${ }^{4}$ e Sérgio Nereu Pagano ${ }^{2}$
}

Recebido em 9/02/2004. Aceito em 2/08/2005.

\begin{abstract}
RESUMO - (Produção, acúmulo e decomposição da serapilheira em uma restinga da Ilha do Mel, Paranaguá, PR, Brasil). Em uma formação de restinga na Ilha do Mel, Paranaguá-PR, foram avaliadas, mensalmente, a serapilheira produzida e a acumulada, em quadrados de $0,25 \mathrm{~m}^{2}$, durante um ano (julho/1996-junho/1997). A decomposição, mensal e anual, foi estimada, indiretamente, pela razão entre serapilheira produzida e acumulada. A produção anual de serapilheira de 5,1 t.ha ${ }^{-1}$ encontra-se no limite inferior aos obtidos em outras florestas tropicais, e decorre, provavelmente, do solo arenoso e pobre em nutrientes. A produção e a decomposição foram sazonais, mais intensa durante o período mais quente e chuvoso, estando relacionadas, principalmente, à temperatura. O pequeno acúmulo de serapilheira $\left(5,5\right.$ t.ha $^{-1}$.ano $\left.{ }^{-1}\right)$, e a ausência de variações mensais significativas neste compartimento denotam o sincronismo entre estes processos, que, aliado a taxa de decomposição anual relativamente baixa $\left(\mathrm{k}_{\mathrm{L}}=0,92\right)$, representa grande valor adaptativo para o ecossistema, pois, pode minimizar as perdas por lixiviação e permitir um melhor aproveitamento dos nutrientes e água disponíveis momentaneamente. Tais mecanismos, bem como o caráter perenifólio das espécies, escleromorfia, e uma rede de raízes superficiais, possibilitam o desenvolvimento da comunidade vegetal sob as condições oligotróficas do solo. Estes, além do clima, parecem exercer uma forte influencia na determinação dos padrões de produção e decomposição da serapilheira.
\end{abstract}

Palavras-chave : produção de serapilheira, serapilheira acumulada, decomposição, restinga, sazonalidade

\begin{abstract}
Litter fall, accumulation and decomposition in a restinga at Ilha do Mel, Paranaguá, Paraná, Brazil). Litter fall and accumulation in restinga vegetation were evaluated monthly in $0.25 \mathrm{~m}^{2}$ quadrats from July 1996 to June 1997 at Ilha do Mel, Paranaguá, Paraná, Brazil. Monthly and annual decomposition were also estimated indirectly by the ratio produced:accumulated litter. Annual litter fall $\left(5.1 \mathrm{t}^{\mathrm{h}} \mathrm{ha}^{-1}\right)$ was low when compared to results found in other tropical forests, probably due to the sandy, nutrient-poor soils. Production and decomposition were seasonal, that is, more intense during the warm, rainy months, and are mainly related to temperature. Monthly changes in litter accumulation were small, as was overall litter accumulation $\left(5.5 \mathrm{t} \mathrm{ha}^{-1}\right.$.year $\left.{ }^{-1}\right)$. The synchronism among these processes and the relatively low annual decomposition rate $(\mathrm{k}=0.92)$ represent adaptations for the ecosystem since they minimize loss from leaching, and allow better use of both nutrients and water at short intervals. Such mechanisms, coupled with the non-deciduous nature of the species, sclerosis, and a network of superficial roots, facilitate plant community development in oligotrophic conditions. These conditions, as well as climate, appear to exercise strong influence in determining patterns of litter production and decomposition.
\end{abstract}

Key words: litterfall, litter standing crop, decomposition, restinga, seasonality

\section{Introdução}

A produção e decomposição da serapilheira são processos fundamentais, e mais comumente mensurados, do fluxo de matéria orgânica e nutrientes da vegetação para a superfície do solo, sendo vitais para o funcionamento do ecossistema, principalmente, nas florestas tropicais situadas em solos pobres em nutrientes (Golley 1978).
A quantia de serapilheira depositada é condicionada por fatores como a latitude (Bray \& Gorham 1964), altitude, precipitação (Londsdale 1988) e evapotranspiração (Meentemeyer et al. 1982). Além destes, aspectos edáficos (Vitousek 1984), e biológicos, como a estrutura (Schlittler et al. 1993; Werneck et al. 2001), idade (Leitão Filho et al. 1993) e composição florística da vegetação (Sundarapandian \& Swamy 1999), também podem afetar a produtividade do

\footnotetext{
1 Parte da Dissertação de Mestrado da primeira Autora. Bolsista do CNPQ

2 Departamento de Botânica, Universidade Estadual Paulista, Av. 24A 1515, CEP 13506-900, Rio Claro,SP, Brasil

3 Sociedade e Pesquisa da Vida Selvagem, Rua Gutemberg 296, CEP 80420-030, Curitiba, PR, Brasil

4 Marine Ecosysten Scientist Parks Canada, 300 - 300 W Georgia Street, Vancouver, BC, Canada

5 Autor para correspondência: luapires@hotmail.com
} 
sistema. A intensidade com que cada fator atua está relacionada às características particulares da fitocenose (W.B.C. Delitti, dados não publicados).

A camada de serapilheira sobre o solo depende, além da produção, da velocidade de decomposição da matéria orgânica, que varia conforme a composição do substrato, atividade dos decompositores e das condições ambientais, particularmente, temperatura, umidade e propriedades físicas do solo (Spain 1984). Quando o ecossistema encontra-se em condição de equilíbrio, a taxa de decomposição pode ser estimada através da razão entre a quantidade de serapilheira produzida e a acumulada, não apresentando, esta última, variações significativas em sua quantidade absoluta (Olson 1963).

A sazonalidade na produção e decomposição de serapilheira tem sido relacionada, principalmente, ao clima (Spain 1984), sendo também mencionados a baixa disponibilidade de nutrientes, estágio sucessional da comunidade e deciduidade das espécies (Vogt et al. 1986; Villela \& Proctor 1999) e outros fatores bióticos, tais como a competição por recursos e comportamento de polinizadores, dispersores e predadores (Janzen 1980).

O termo "restinga", no sentido fitogeográfico, designa todas as formações vegetais que ocorrem sobre as planícies quaternárias litorâneas (Silva \& Britez 2005), as quais ocupam cerca de $70 \%$ do litoral brasileiro (Araújo 1992), e cobrem aproximadamente $90 \%$ da área da Ilha do Mel (Britez et al. 1997). Assim como os demais ecossistemas do Complexo Mata Atlântica, a restinga vem sofrendo intensa degradação devido à expansão urbana e à exploração econômica, sendo ainda escassas as informações acerca da sua ecologia. Este trabalho é parte do estudo de ciclagem de nutrientes realizado em florestas de restinga na Ilha do Mel, PR, que visa contribuir para o conhecimento do funcionamento deste ecossistema, e fornecer dados para sua conservação e manejo. Tem como objetivo específico avaliar a produção, acúmulo e, indiretamente, a decomposição da serapilheira, relacionando-a a fatores ambientais.

\section{Material e métodos}

Área de Estudo - A Ilha do Mel localiza-se na entrada da Baia de Paranaguá (2529'29"'-25³4'32”S e 48¹7'15"-48²3'16”'W), no município de Paranaguá, Estado do Paraná. Possui uma extensão de 2.760 ha, formada por vários morros interligados pelas planícies arenosas, constituídas por cordões litorâneos e dunas originados da deposição marinha, em sua maior parte, quaternária (Bigarella 1965). O clima do litoral paranaense é considerado como de transição entre a região tropical e subtropical (Maack 1981), incluindo-se, segundo a classificação Köppen, na zona climática Af, acrescentando a letra " $t$ " para indicar esta transição. As cartas climáticas elaboradas pelo Iapar (1978) caracterizam o clima como mesotérmico, superúmido, sem estação seca rigorosa, e isentos de geada. Os dados climáticos do período de estudo foram fornecidos pelo Laboratório de Física Marinha do Centro de Estudos do Mar, Universidade Federal do Paraná, situado no município de Pontal do Paraná, PR; os dados do período entre 1948-1988 foram obtidos na Estação Meteorológica de Paranaguá, PR por S.M. Silva, dados não publicados. A temperatura média anual $\left(21,1^{\circ} \mathrm{C}\right)$ foi semelhante entre estes dois períodos; a precipitação anual durante o período de estudo foi de $1.429 \mathrm{~mm}$, menor que o período de 41 anos $(1.959 \mathrm{~mm})$. A média anual da velocidade do vento foi de $3,5 \mathrm{~m} . \mathrm{s}^{-1}$, com sazonalidade que acompanha a temperatura e precipitação, mais elevada durante o verão. A umidade relativa do ar foi alta durante o ano todo (Fig. 1A; B). Pequenos déficits hídricos, considerando $25 \mathrm{~mm}$ como capacidade de retenção do solo, foram registrados em novembro e dezembro/1996 e julho/1997 (1, 6, e 1 mm, respectivamente), e pouco mais elevados em fevereiro, atribuída a uma baixa pluviosidade atípica neste mês, e abril/1997 (64 e $36 \mathrm{~mm}$, respectivamente), repostos nos meses seguintes.

A comunidade vegetal estudada situa-se numa estreita faixa paralela ao mar, na depressão após a primeira duna estabelecida; encontra-se bem preservada, sendo transformada em 2002, em Parque Estadual da Ilha do Mel (Decreto Estadual 5506). S.M. Silva (dados não publicados) descreve a vegetação como fisionomicamente homogênea, com um dossel contínuo que alcança $5 \mathrm{~m}$ de altura (média de $3 \mathrm{~m}$ ), densidade total de 4.890 ind/ha e área basal de $35 \mathrm{~m}^{2} \cdot \mathrm{ha}^{-1}$ (DAP $\geq 5 \mathrm{~cm}$ ). No levantamento florístico, o autor encontrou 34 espécies arbóreas distribuídas em 19 famílias.

O solo, segundo a nomenclatura da EMBRAPA (1999), foi classificado como Espodossolo Cárbicoórtico Espessarênico ácido e, exceto no horizonte mais superficial, com baixa quantidade de bases trocáveis, sendo a maioria da CTC ocupada por alumínio e hidrogênio (L.A. Pires, dados não publicados).

Produção de serapilheira - A serapilheira produzida foi avaliada, mensalmente, durante um ano, através de 


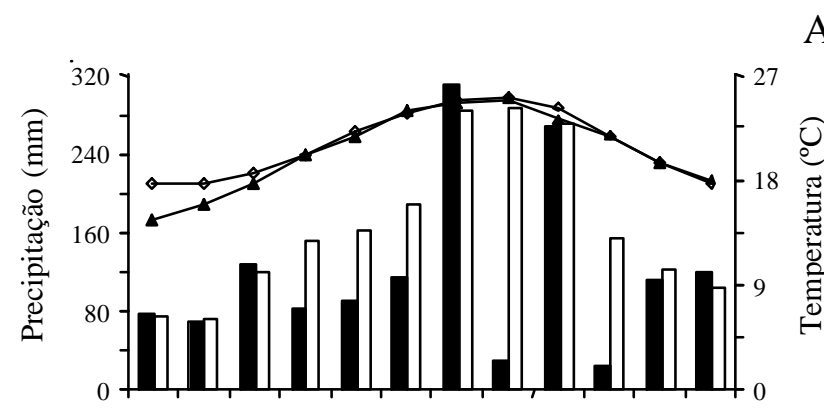

B

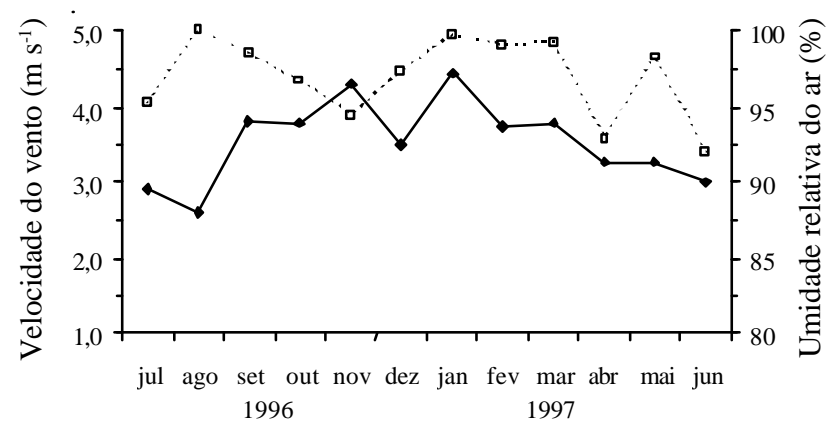

Figura 1. Dados climáticos mensais da região da Ilha do Mel, Paranaguá, PR, Brasil. A. Temperatura média do período de estudo (-^-) e médias de 1948 a 1988 (-४-); precipitação do período

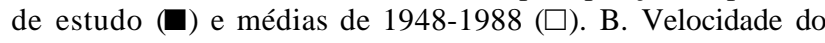
vento $(-\rightarrow)$ e umidade relativa do ar (- - ) do período de estudo.

40 coletores de fibra de vidro $\left(0,25 \mathrm{~m}^{2}\right)$ com tela de náilon $\left(4 \mathrm{~mm}^{2}\right)$, instalados a $20 \mathrm{~cm}$ acima do nível do solo, em junho/1996, sendo distribuídos dois coletores (um voltado em direção ao mar e outro ao interior) em cada parcela $(10 \times 10 \mathrm{~m})$ utilizada na fitossociologia realizada por Silva \& Britez (2005). A serapilheira recolhida foi parcialmente seca à temperatura ambiente, e submetida à triagem em quatro frações: folhas (separadas, quando possível, por espécie), ramos e galhos (diâmetro $\leq 2 \mathrm{~cm}$ ), órgãos reprodutivos (flores, frutos e sementes) e miscelânea (todo material que não se enquadrava nas demais frações); posteriormente, as amostras foram seca em estufa a $70{ }^{\circ} \mathrm{C}$ até a obtenção de peso constante.

Serapilheira acumulada e decomposição - A estimativa, mensal, da serapilheira acumulada foi por meio da retirada, em 10 quadrados $\left(0,25 \mathrm{~m}^{2}\right)$, de todo material orgânico (exceto ramos $\geq 2 \mathrm{~cm}$ de diâmetro) sobre o solo mineral, sendo escolhidos, aleatoriamente, um ponto por parcela onde estavam os coletores. $\mathrm{O}$ mesmo procedimento realizado com a serapilheira produzida foi adotado, sendo as amostras separadas em fração lenhosa e não lenhosa, a qual foi denominada de "fração foliar" por ser o material preponderante, embora tenham sido incluídos flores e frutos.

Para estimar a decomposição do material acumulado sobre o solo, foi utilizada a equação desenvolvida por Olson (1963), admitindo-se situação de equilíbrio, sendo:

$\mathrm{k}_{\mathrm{L}}=\mathrm{I} / \mathrm{X}$ (equação 1 ) onde:

$\mathrm{k}_{\mathrm{L}}=$ coeficiente de decomposição

$\mathrm{I}=$ quantidade de serapilheira produzida anualmente em kg.ha ${ }^{-1}$

$\mathrm{X}=$ quantidade de serapilheira acumulada em kg.ha ${ }^{-1}$

A mesma fórmula foi aplicada para obtenção deste índice mensalmente, utilizado-se dos dados deste período.

O tempo médio necessário para renovação do estoque de serapilheira foi obtido através da equação (2) $t_{R}: 1 / k_{L}$ (Hopkins 1966), expressa em anos.

Análises estatísticas - Para a análise da variação mensal da produção de serapilheira total e fracionada, foi utilizada a análise de variância (ANOVA), seguida por comparação de médias (teste de Scheffe; $p<0,05$ ), no caso das variâncias terem se revelado homogêneas (teste de O'Brien), e a distribuição dos dados se ajustado à normal (teste de Shapiro-Wilk). Quando necessário, os dados foram submetidos à transformação logarítmica. A correlação entre dados climáticos (precipitação, temperatura média e máxima, velocidade do vento, umidade relativa do ar) e de produção e acúmulo da serapilheira foi analisada por intermédio da matriz de correlação de Pearson. No caso da fração reprodutiva, os dados não apresentaram distribuição normal, usando-se nesse caso, para a análise comparativa da produção mensal, o teste de KruskalWallis seguido pelos intervalos de confiança $(\mathrm{p}<0,05)$ (Campos 1983), e o coeficiente de Spearman, para o teste de correlação entre os fatores climáticos. A relação entre os dados climáticos com os de produção e acúmulo da serapilheira também foi testada através da análise de regressão passo-a-passo (stepwise).

\section{Resultados}

Produção de serapilheira - A produção anual de serapilheira foi estimada em $5.080 \mathrm{~kg} \cdot \mathrm{ha}^{-1}$, constituída por $74,6 \%$ de folhas $\left(3.791 \mathrm{~kg}^{-h^{-1}}\right), 18,1 \%$ de ramos (917 kg.ha $\left.{ }^{-1}\right), 4,8 \%$ de órgãos reprodutivos $\left(2.46 \mathrm{~kg} \mathrm{ha}^{-1}\right)$ e $2,5 \%$ de miscelânea $\left(1.26 \mathrm{~kg} \mathrm{ha}^{-1}\right)$. A deposição da serapilheira total, bem como das suas frações, foi mais intensa no período de outubro a janeiro, quando foram transferidos para o solo 53,9\% do total anual. Para a fração reprodutiva, embora a análise de variância entre as produções mensais tenha 
sido significativa $(\mathrm{H}=112 ; \mathrm{p}<0,0001)$, o teste de comparação de médias não apontou diferenças estatísticas (Fig. 2).

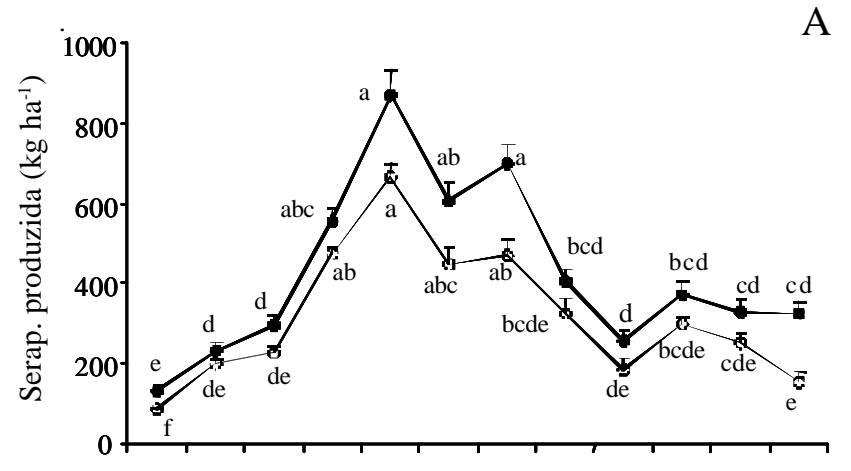

B

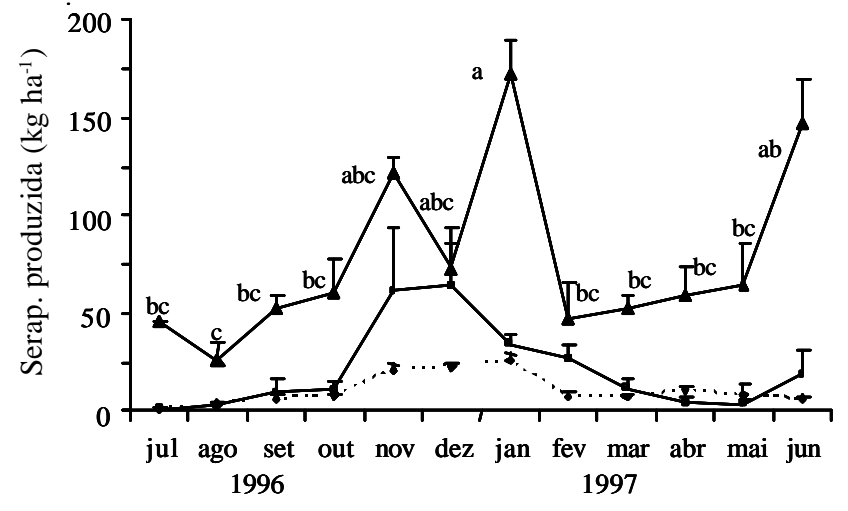

Figura 2. Produção mensal de serapilheira, total e fracionada, na restinga da Ilha do Mel, PR, Brasil. A. Serapilheira - •- Total e -o-Foliar. B. -ム- Fração Ramos; -ø-Reprodutiva e ------ Miscelânea. Barras indicam o erro-padrão. *Médias seguidas da mesma letra não diferem significativamente (teste de Scheffe), ao nível de $\mathrm{p}<0,05$.
A deposição total e das frações foliar, reprodutiva e miscelânea foram correlacionadas entre si, e diretamente com a temperatura média e velocidade do vento do período de estudo, além de temperatura máxima (média de 41 anos) para a primeira. A fração reprodutiva apresentou ainda correlação significativa (Spearman) com precipitação e temperatura média do período de 41 anos (Tab. 1). A umidade do ar e a precipitação do período de estudo não foram correlacionadas significativamente a nenhuma variável analisada. Na regressão, a temperatura média foi a única variável com efeito significativo $(n=12$; $\mathrm{p}<0,05)$ na deposição total, e nas frações foliar, reprodutiva e miscelânea (Fig. 3). A velocidade do vento e a temperatura máxima foram excluídas da análise por apresentarem alta correlação com a temperatura média (Tab. 1), e, por ser este último fator o mais comumente relacionado à produção de serapilheira, foi preferencialmente utilizado. A fração ramos não apresentou na matriz de correlação resultados significativos com as variáveis climáticas (Tab. 1), possivelmente pelos altos valores de erropadrão e por algumas variáveis serem correlacionadas, ocorrendo multicolinearidade. Tal efeito pode ser removido com o uso da correlação parcial; desta forma, a velocidade do vento apresentou a maior correlação $(p<0,05)$ com a fração ramos $(r=0,80)$ seguida pela temperatura máxima $(r=0,76)$, temperatura média $(\mathrm{r}=-0,76)$ e precipitação $(\mathrm{r}=0,76)$. Na análise de regressão, todos os parâmetros climáticos avaliados foram significativos (Dep.Ramos $=6,198+0,483$ ppt - 0,062umid. + 0,033temp.méd.; $\left.\mathrm{R}^{2}=0,76 ; \mathrm{n}=12 ; \mathrm{p}<0,05\right)$.

Tabela 1. Resultados das análises de correlação entre os dados climáticos e os de produção e acúmulo da serapilheira, total e fracionada, obtidos na restinga da Ilha do Mel, PR, Brasil. FOL - fração foliar; TT - deposição total; RM - log (ramos +1); MIS - log (miscelânea +1); TM - Temperatura média do período de estudo; TMD - Temperatura média de 41 anos; PPT - Precipitação média de 41 anos; VV - Velocidade média do vento no período de estudo; TMX - Temperatura máxima do período de estudo; SAF - Serapilheira acumulada fração foliar. REP - fração reprodutiva.

\begin{tabular}{|c|c|c|c|c|c|c|c|c|c|c|}
\hline & $\mathrm{TT}$ & FOL & $\mathrm{RM}$ & MIS & $\mathrm{TM}$ & TMD & PPT & VV & TMX & SAF \\
\hline FOL & $97 *$ & & & & & & & & & \\
\hline $\mathrm{RM}$ & $65^{*}$ & 48 & & & & & & & & \\
\hline MIS & $88 *$ & $83 *$ & $64 *$ & & & & & & & \\
\hline $\mathrm{TM}$ & $61 *$ & $59 *$ & 39 & $80 *$ & & & & & & \\
\hline TMD & 53 & 52 & 28 & $69 *$ & $96 *$ & & & & & \\
\hline PPT & 41 & 38 & 29 & 57 & $91 *$ & $95 *$ & & & & \\
\hline VV & $76^{*}$ & $73 *$ & 56 & $73 *$ & $69 *$ & $69 *$ & $71 *$ & & & \\
\hline TMX & $58 *$ & 55 & 43 & $79 *$ & $99 *$ & $94 *$ & $89 *$ & $64 *$ & & \\
\hline SAF & 28 & 20 & 31 & 55 & $59 *$ & 54 & 43 & 08 & $64 *$ & \\
\hline $\operatorname{REP}\left(\mathrm{r}_{\mathrm{s}}\right)$ & $79 *$ & $62 *$ & $66^{*}$ & $69^{*}$ & $74 *$ & $70 *$ & $73 *$ & $62 *$ & $74^{*}$ & -02 \\
\hline
\end{tabular}

* Resultados significativos, ao nível de $\mathrm{p}<0,05$, da correlação de Pearson, exceto fração reprodutiva, $\mathrm{r}_{\mathrm{s}}$, de Spearman. 

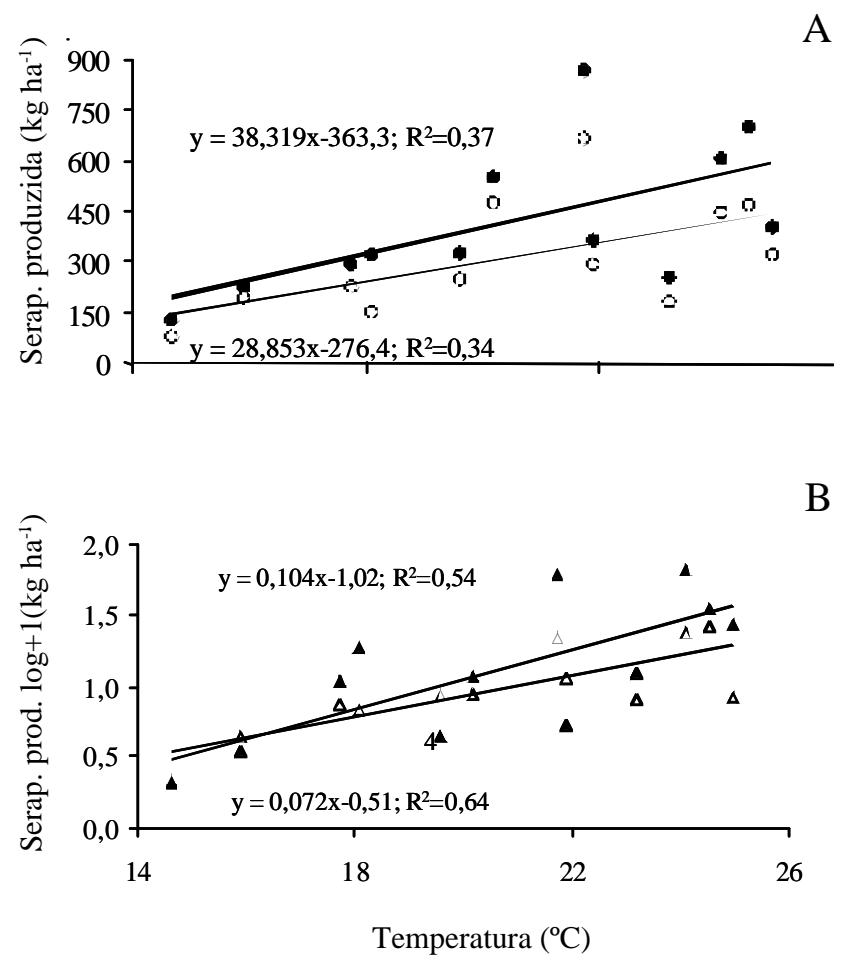

Figura 3. Linhas de regressão da produção de serapilheira com a temperatura média do período de estudo. A. Serapilheira total (o) e foliar $(\bullet)$. B. Fração reprodutiva $(\Delta)$ e miscelânea $(\triangle)$. n=12; $\mathrm{p}<0,05$.

A contribuição percentual de Ternstroemia brasiliensis, Tapirira guianensis, Guapira opposita, Ilex theezans, Clusia criuva, Ocotea pulchella e Pera glabrata constituíram $71 \%$ da fração foliar total da serapilheira, e seguem, as três primeiras, aproximadamente a ordenação de seus respectivos índices de dominância obtidos na fitossociologia por S.M. Silva (dados não publicados)

Tabela 2. Produção anual de folhas das espécies de maior contribuição na serapilheira foliar, seus percentuais em relação ao total produzido por esta fração, e os valores de densidade (DR) e dominância relativa (DoR) obtidos por S.M. Silva (dados não publicados)*, na restinga da Ilha da Mel, PR, Brasil.

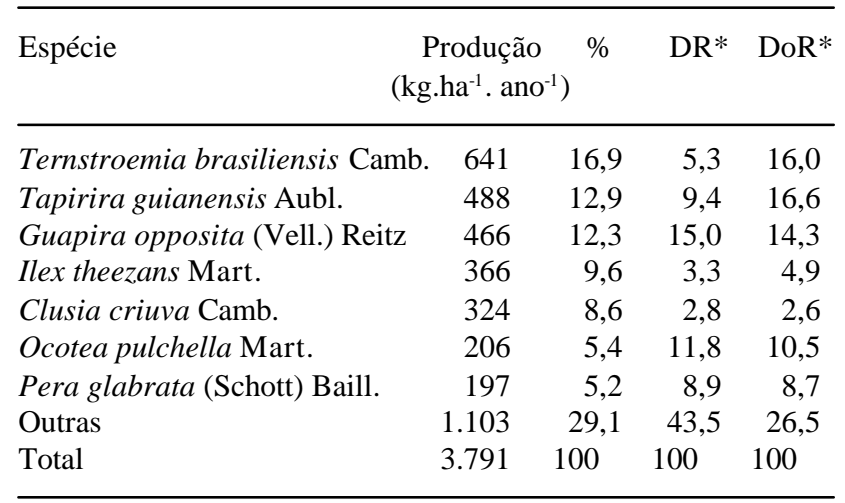

(Tab. 2). O padrão sazonal de queda foliar destas acompanha, em geral, o da fração foliar total (Fig. 4), sendo significativamente correlacionadas a temperatura, com exceção de I. theezans, e velocidade do vento, exceto para $T$. guianensis (Tab. 3). Através dos resultados das análises de regressão $(\mathrm{p}<0,05)$, incluindo ora velocidade do vento, ora temperatura média, pode ser distinguido dois grupos, T. guianensis $(-49,88+4,41 T$.M.; $\left.\mathrm{R}^{2}=0,38\right)$, C. criuva $\left(-47,05+3,60 \mathrm{~T} . \mathrm{M} . ; \mathrm{R}^{2}=0,47\right)$ e O. pulchella $\left(-, 053+0,08 \mathrm{~T} . \mathrm{M} . ; \mathrm{R}^{2}=0,48\right)$, onde a temperatura se mostra mais influente na deposição foliar, e $G$. opposita $\left(0,63+0,26 \mathrm{~V} . \mathrm{V}\right.$.; $\left.\mathrm{R}^{2}=0,47\right)$, I. theezans $\left(-0,15+0,43 \mathrm{~V} . \mathrm{V}\right.$.; $\left.\mathrm{R}^{2}=0,43\right) \mathrm{e}$ P. glabrata $\left(-0,97+0,57 \mathrm{VV} ; \mathrm{R}^{2}=0,54\right)$, tendo a velocidade do vento como principal fator. Apenas O. pulchella apresentou variação mensal significativa $(H=39,4 ; p=0,006)$, com produção foliar mais intensa em janeiro do que os meses de julho e agosto. Nenhuma variável climática avaliada foi relacionada significativamente à deposição foliar de T. brasiliensis.

Serapilheira acumulada - A média anual da serapilheira acumulada total foi $5.542 \mathrm{~kg} \cdot \mathrm{ha}^{-1} \mathrm{ano}^{-1}$, constituída de
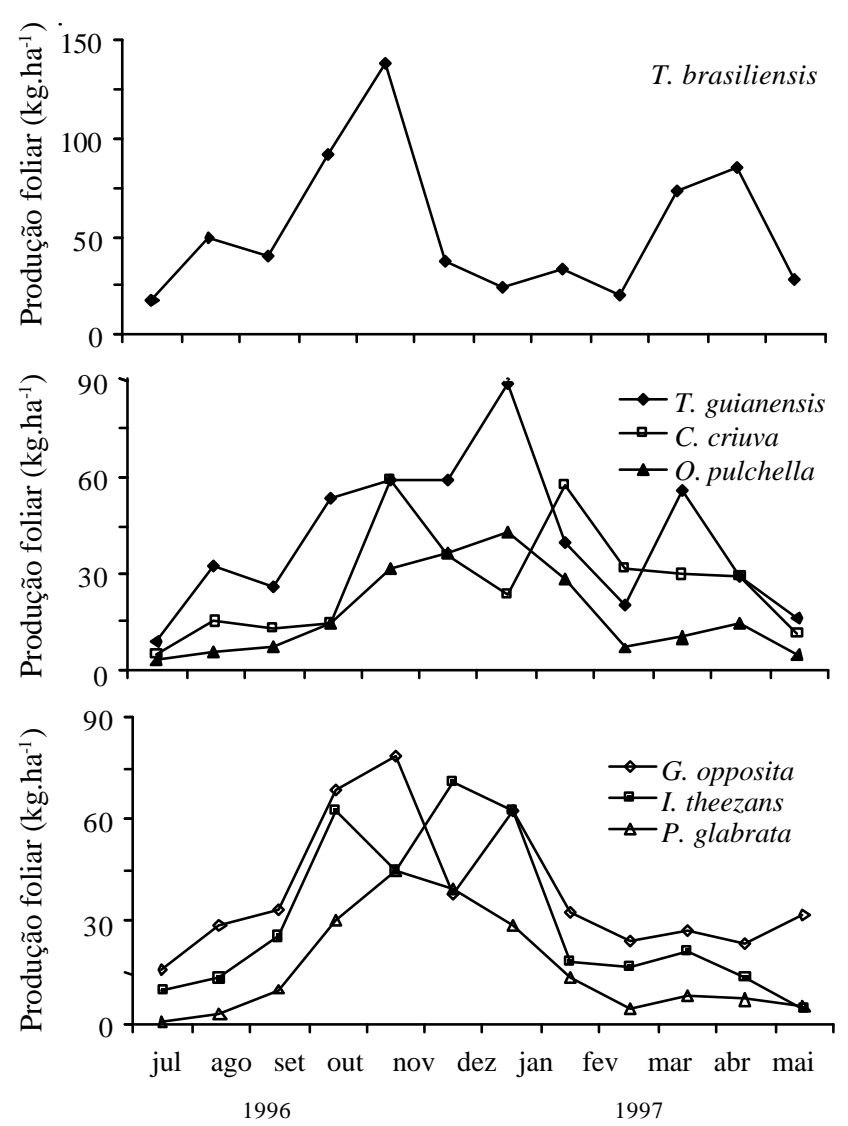

Figura 4. Estimativa da produção mensal da serapilheira foliar das principais espécies na Restinga da Ilha do Mel, PR, Brasil. 
Tabela 3. Resultados da correlação de Spearman $\left(r_{s}\right)$ entre as deposições mensais de serapilheira das principais espécies com a temperatura média e a velocidade do vento do período de estudo.

\begin{tabular}{lccccr}
\hline \multirow{2}{*}{ Espécies } & \multicolumn{2}{c}{ Temp. média } & & \multicolumn{2}{c}{ Vel. vento } \\
\cline { 2 - 3 } \cline { 6 - 7 } & $\mathrm{r}_{\mathrm{s}}$ & $\mathrm{p}$ & & $\mathrm{r}_{\mathrm{s}}$ & $\mathrm{p}$ \\
\hline T. guianensis & 0,64 & 0,03 & & 0,55 & $\mathrm{~ns}$ \\
G. opposita & 0,64 & 0,03 & & 0,69 & 0,01 \\
I. theezans & 0,56 & $\mathrm{~ns}$ & & 0,70 & 0,01 \\
C. criuva & 0,78 & 0,003 & & 0,70 & 0,01 \\
O. pulchella & 0,77 & 0,003 & & 0,69 & 0,01 \\
P. glabrata & 0,59 & 0,04 & & 0,70 & 0,01 \\
\hline
\end{tabular}

$\mathrm{ns}=$ não significativo ao nível de $\mathrm{p}<0,05 . \mathrm{n}=12$

$4.486 \mathrm{~kg} \cdot \mathrm{ha}^{-1} \mathrm{ano}^{-1}$ pela fração foliar $(81 \%)$ e de $1.047 \mathrm{~kg} \cdot \mathrm{ha}^{-1} \mathrm{ano}^{-1}$ pela fração lenhosa $(19 \%)$, percentuais similares ao observado na serapilheira produzida.

Para a distribuição da serapilheira acumulada, total e fracionada, ao longo do ano, não foi encontrada diferença significativa entre os meses nem entre as estações do ano (Fig. 5). Apenas serapilheira acumulada foliar apresentou correlação significativa direta com temperatura média e máxima do período estudado (Tab. 1). Na regressão, a temperatura média foi a única variável relacionada $(\mathrm{p}<0,05)$ a serapilheira acumulada foliar e lenhosa (Fig. 6).

$\mathrm{O}$ coeficiente de decomposição anual, $\mathrm{k}_{\mathrm{L}}$ (equação 1), e o tempo médio de renovação, $\mathrm{t}_{\mathrm{r}}$ (equação 2), estimados para a serapilheira total foram, respectivamente, 0,92 e 1,09 anos, sendo obtido valores próximos entre as frações foliar e lenhosa $\left(\mathrm{k}_{\mathrm{L}}: 0,93 \mathrm{e}\right.$ 0,88, e $_{\mathrm{r}}: 1,09$ e 1,14 anos, respectivamente). As taxas mensais de decomposição das frações e do total da serapilheira acumulada variaram de 0,02 a $0,18 \mathrm{com}$

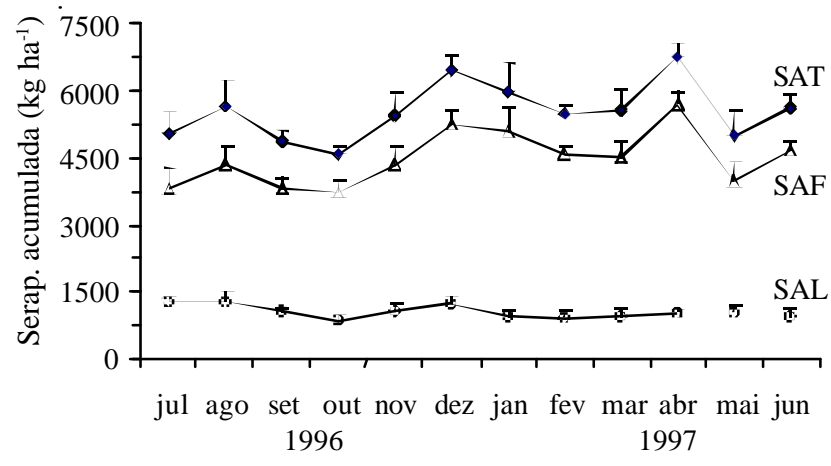

Figura 5. Estimativas mensais (médias em kg.ha-1) da serapilheira acumulada total (SAT) e das suas frações, foliar (SAF) e lenhosa (SAL), na restinga da Ilha do Mel, PR, Brasil. Barras indicam o erro-padrão. picos em novembro (foliar e total) e janeiro (fração lenhosa) (Fig. 7).

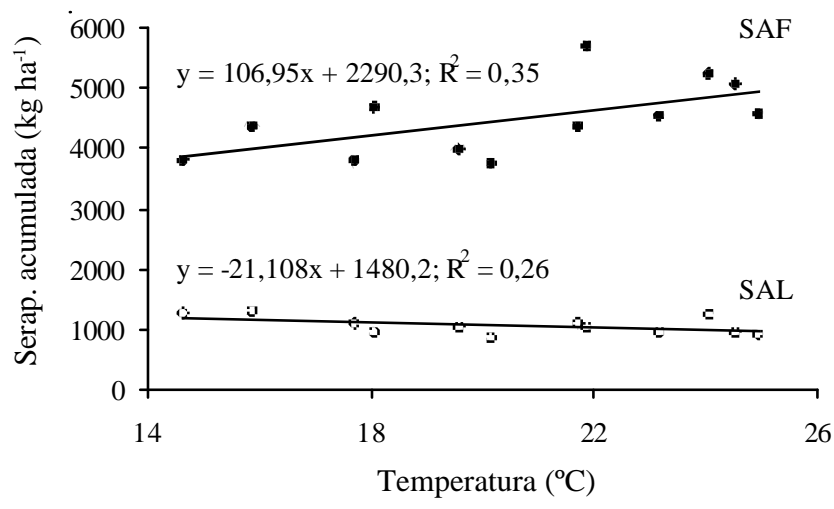

Figura 6. Linhas de regressão da serapilheira acumulada foliar (SAF) e lenhosa (SAL) com a temperatura média do período de estudo na Ilha do Mel, PR, Brasil. $\mathrm{n}=12 ; \mathrm{p}<0,05$.

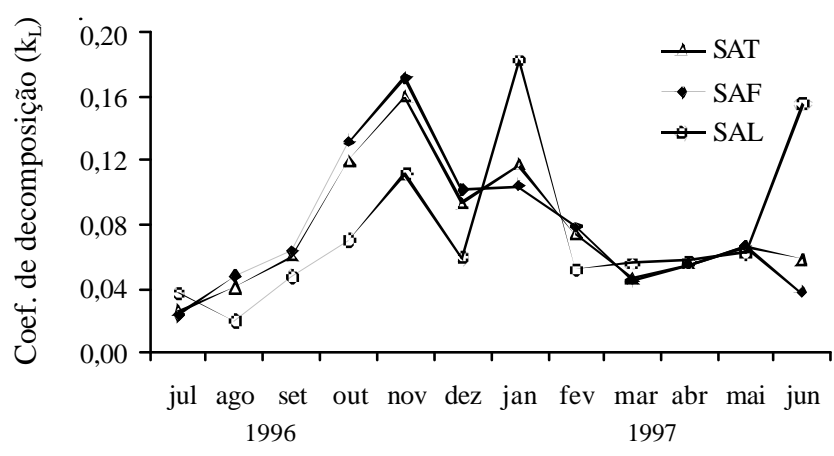

Figura 7. Estimativas das taxas mensais de decomposição da serapilheira $\left(\mathrm{k}_{\mathrm{L}}\right)$, obtidas na Restinga da Ilha do Mel, PR, Brasil. SAT $=$ Serapilheira Acumulada Total $;$ SAF $=$ Serapilheira Acumulada Foliar; SAL = Serapilheira Acumulada Lenhosa.

\section{Discussão}

Produção de serapilheira - A produção anual de serapilheira estimada no presente estudo $\left(5,1\right.$ t. ha.ano $\left.{ }^{-1}\right)$ é inferior ao previsto para florestas situadas em latitudes de $25^{\circ}$, de 7 a 8,8 t.ha.ano ${ }^{-1}$ (Bray \& Gorham 1964), porém dentro da faixa obtida para outras restingas. Este fato decorre, provavelmente, do solo arenoso e pobre em nutrientes, sendo encontrado valores inferiores apenas em outros ecossistemas sob condições oligotróficas, tais como áreas de cerrado e caatinga amazônica (Tab. 5). A influência na determinação da produtividade do sistema de características como a fertilidade, umidade e textura do solo foi constatada por vários autores que estudaram áreas próximas entre si (Peres et al. 1983; Cuevas \& Medina 1986; Britez et al. 2005; Moraes et al. 1999). 
A serapilheira produzida nas florestas de restinga, embora relativamente baixa, é muito importante para este sistema, pois além da entrada de nutrientes, promove melhores condições do solo através da regulação do $\mathrm{pH}$, e aumento do armazenamento de água, nutrientes e capacidade de troca catiônica (Hay
\& Lacerda 1984; Moraes et al. 1999). A variação na produtividade entre elas deve resultar da sua grande heterogeneidade ambiental, as quais apresentam distintas composições florísticas, estruturais e funcionais, conforme estejam estabelecidas sobre ou entre cordões litorâneos, do nível do lençol freático, e

Tabela 4. Estimativas da serapilheira produzida total e foliar, acumulada e as taxas de decomposição ( $\mathrm{k}_{\mathrm{L}}$ serap. produzida/serap.acumulada) calculadas em alguns ecossistemas tropicais.

\begin{tabular}{|c|c|c|c|c|c|}
\hline Ecossistema/local & SP & Fol & SA & $\mathrm{k}_{\mathrm{L}}$ & Autores \\
\hline \multicolumn{6}{|l|}{ Floresta de restinga } \\
\hline RJ - Maricá & 6,2 & & & & Ramos \& Pellens (1994) \\
\hline SP - Ilha do Cardoso & 3,9 & 74 & 3,6 & 1,07 & Moraes et al. $(1998 ; 1999)$ \\
\hline \multicolumn{6}{|l|}{ PR - Ilha do Mel } \\
\hline Floresta periodicamente inundável & 6,6 & & 4,8 & 1,37 & Britez \& Pires (dados não publicados) \\
\hline Floresta não inundável & 5,8 & & 5,2 & 1,12 & Britez \& Pires (dados não publicados) \\
\hline Floresta periodicamente inundável & 7,7 & 73 & & & Britez et al. (2005) \\
\hline Floresta não inundável & 5,2 & 62 & & & Britez et al. (2005) \\
\hline Restinga pós-praia & 5,1 & 75 & 5,5 & 0,92 & Este estudo \\
\hline \multicolumn{6}{|l|}{ Floresta Atlântica } \\
\hline SP- Guarujá & 7,9 & 63 & 10,9 & 0,72 & Varjabedian \& Pagano (1989) \\
\hline \multicolumn{6}{|l|}{ SP- Cubatão/ Secundária } \\
\hline menos poluída - rio Pilões & 5,7 & 81 & 3,9 & 1,46 & Leitão-Filho et al (1993) \\
\hline mais poluída - rio Mogi & 4,5 & 80 & 4,1 & 1,09 & Leitão-Filho et al (1993) \\
\hline SP- Ilha do Cardoso & 6,3 & 70 & 3,2 & 1,90 & Moraes et al. $(1998 ; 1999)$ \\
\hline \multicolumn{6}{|l|}{ RJ - Campo dos Goytacazes } \\
\hline Floresta à $50 \mathrm{~m}$ altitude & 9,5 & 67 & 6,1 & 1,54 & Mazurec \& Villela (1998) \\
\hline Floresta à $200 \mathrm{~m}$ altitude & 9,1 & 64 & 7,4 & 1,22 & Mazurec \& Villela (1998) \\
\hline \multicolumn{6}{|l|}{ Floresta Estacional } \\
\hline SP - Rio Claro & 8,6 & 63 & 5,7 & 1,50 & Pagano (1989) \\
\hline SP- Jundiaí & 8,6 & 64 & 5,5 & 1,60 & Morellato (1992) \\
\hline SP-Anhembi & 8,8 & 65 & 8,6 & 1,10 & César (1993) \\
\hline SP - Araras & 8,8 & 66 & 8,2 & 1,40 & Diniz \& Pagano (1997) \\
\hline \multicolumn{6}{|c|}{ RJ - São Francisco de Itabapoana/ Floresta Atl. de Tabuleiro } \\
\hline sem corte seletivo recente & 7,6 & 70 & 20,0 & 0,38 & Villela et al (1998) \\
\hline com corte seletivo & 7,9 & 69 & 17,5 & 0,45 & Villela et al (1998) \\
\hline \multicolumn{6}{|l|}{ Floresta Amazônica } \\
\hline PA - Belém/ Terras Baixas & 9,9 & 81 & 6,6 & & Klinge (1977) \\
\hline Venezuela - San Carlos/Terra Firme & 10,3 & 74 & & & Cuevas \& Medina (1986) \\
\hline 'Caatinga' Alta & 5,6 & 71 & & & Cuevas \& Medina (1986) \\
\hline 'Caatinga' Baixa & 2,4 & 88 & & & Cuevas \& Medina (1986) \\
\hline RR - Ilha de Maracá: Terras Baixas & 9,3 & 68 & 4,6 & 2,00 & Scott et al. (1992) \\
\hline Dominada por Peltorogyne gracilipes & 7,9 & 70 & & & Villela \& Proctor (1999) \\
\hline Floresta pobre em $P$. gracilipes & 9,1 & 66 & & & Villela \& Proctor (1999) \\
\hline Floresta sem $P$. gracilipes & 8,6 & 70 & & & Villela \& Proctor (1999) \\
\hline PA - Terras Baixas & 9,7 & 70 & 7,2 & 1,34 & Smith et al. (1998) \\
\hline \multicolumn{6}{|l|}{ Outras Formações Tropicais } \\
\hline SP - Moji-Guaçu/ Mata ciliar & 6,7 & & 11,3 & 0,59 & W.B.C Delitti (dados nãopublicados) \\
\hline SP - Moji-Guaçu/ Campo cerrado & 3,2 & & 8,2 & 0,39 & W.B.C Delitti (dados não publicados) \\
\hline SP - Jundiaí/ Floresta de Altitude & 7,0 & 70 & 5,5 & 1,30 & Morellato (1992) \\
\hline RS - Santa Maria/ Floresta Decidual & 9,2 & 67 & & & König et al. (2002) \\
\hline Sarawak - Floresta Aluvial & 11,5 & 57 & & & Proctor et al. (1983) \\
\hline Keranga -Heath Forest & 9,2 & 61 & & & Proctor et al. (1983) \\
\hline Dipterocarpos & 8,8 & 61 & & & Proctor et al. (1983) \\
\hline \multicolumn{6}{|l|}{ Jamaica - Floresta úmida de encosta } \\
\hline primária & 9,5 & 78 & 4,3 & 2,21 & McDonald \& Healey (2000) \\
\hline secundária & 7,0 & 86 & 2,7 & 2,56 & McDonald \& Healey (2000) \\
\hline
\end{tabular}


da distância do oceano (Silva \& Britez 2005).

A contribuição da fração foliar para a serapilheira total $(74,6 \%)$ está entre as mais altas relatadas na literatura (Tab. 5), sendo maior do que o calculado $(62,4 \%)$ para florestas tropicais (Bray \& Gohram 1964), próxima a de outras florestas situadas em solos de baixa fertilidade (Klinge 1977; Cuevas \& Medina 1986; Moraes et al. 1999) e inferior a de florestas com distúrbios (Leitão Filho et al. 1993; Donald \& Healey 2000). O alto percentual de folhas tem sido freqüentemente associado à presença de espécies pioneiras, as quais possuem um rápido crescimento; entretanto, na comunidade estudada este grupo de plantas é pouco freqüente, e este resultado deve estar mais relacionado ao estresse (Tanner 1980), condicionado no local, além da oligotrofia, pelo constante impacto nas gemas das plantas da areia e sal trazidos pelo vento (salsugem), acarretando uma necessidade de contínua renovação das folhas. Segundo S.M. Silva (comunicação pessoal) a influência da salsugem nesta formação é evidenciada por uma área basal elevada e uma baixa altura do dossel, se comparada às outras fisionomias mais interiorizadas da Ilha.

A abrasão marinha pode também afetar a produção de elementos reprodutivos, os quais tiveram um percentual relativamente baixo (5\%). Entretanto, considerando seus elevados erros-padrão mensais (Fig. 2B), atribuído, além da baixa quantidade produzida, às variações morfo e fenológicas entre as espécies, este resultado também pode decorrer da imprecisão do método para sua amostragem, como salientado por Moraes et al. (1999), que estimaram percentual semelhante para esta fração.

A separação específica da fração foliar é raramente descrita em florestas tropicais, embora seja de grande importância, pois podem fornecer dados acerca da fenologia, nutrição e padrões da ciclagem de nutrientes do sistema (Malaisse et al. 1975; Vitousek 1982; Britez et al. 1992; Moraes \& Domingos 1997; Villela \& Proctor 1999). As folhas de T. brasiliensis, T. guianensis e G. opposita, as mais importantes na estrutura da floresta (Silva \& Britez 2005), representaram quase metade do total anual da serapilheira foliar, denotando o papel fundamental no funcionamento desta e em outras formações de restinga na Ilha (R.M. Britez, dados não publicados). O tamanho e porte dos indivíduos mostraram uma relação mais estreita com a queda foliar do que a densidade, corroborando o proposto por Schlittler et al. (1993), Williams-Linera \& Tolome (1996) e Werneck et al.
(2001). Provavelmente, a ausência de equivalência entre os índices fitossociológicos e a deposição foliar para as demais espécies amostradas (Tab. 2) resulta das características morfológicas das folhas (tamanho e escleromorfia), enquanto em Floresta Atlântica, este fato foi associado à alta diversidade da comunidade (Mazurec \& Villela 1998).

A maior deposição de serapilheira, bem como das folhas das principais espécies, coincidiu com a estação mais quente e chuvosa (Fig. 1, 2 e 4), sendo relacionadas diretamente a temperatura média do período de estudo, verificado também em florestas de restinga (Britez et al. 2005), e velocidade do vento, provavelmente pelo efeito mecânico exercido sobre a copa das árvores, embora deva ser ressaltada sua correlação direta com a temperatura (Tab. 1). Outros autores descrevem a influencia do vento na deposição de serapilheira (Proctor et al. 1983; Sundarapadian \& Swany 1999) e queda foliar específica (Staelens et al. 2003). Na área de estudo, torna-se particularmente importante devido à proximidade com o mar aberto, sendo preponderante para a deposição de folhas de G. opposita, P. glabrata e I. theezan. Já a temperatura parece determinar a queda foliar de T. guianensis, O. pulchella e C. criuva (Tab. 3). Williams-Linera \& Tolome (1996) também encontraram correlações positivas com a temperatura e não significativas com a precipitação para a deposição de folhas de espécies tropicais, em contraste com as correlações negativas com temperatura mínima e precipitação para as espécies temperadas, aferindo o controle distinto dos fatores climáticos à origem fitogeográfica das espécies.

Este padrão sazonal da produção da serapilheira, caracterizado pelas folhas, ocorre em regiões com moderada sazonalidade climática (Proctor et al. 1983; Britez et al. 2005; Mazurec \& Villela 1998; Moraes et al. 1999), e por ser um processo simultâneo à produção de folhas novas, pode possibilitar uma economia energética na transferência de substâncias das folhas senescentes para aquelas em desenvolvimento (Jackson 1978). Nas formações de restinga, este processo pode ser ainda beneficiado pelo aumento na disponibilidade de nutrientes para as plantas através do lençol freático, o qual, com as chuvas intensas do verão torna-se mais superficial, permitindo a ascensão dos nutrientes até o alcance das raízes (Britez et al. 2005).

Como exceção em área do Complexo Mata Atlântica pode ser citado o trabalho de Ramos \& Pellens (1993), que em uma restinga de Maricá, RJ, 
onde ocorre déficit hídrico e média anual de precipitação relativamente baixa, estimaram uma maior produção de serapilheira nos meses de julho a novembro, após o déficit, padrão semelhante ao encontrado em florestas tropicais estacionais (Tanner 1980; Pagano 1989; Morellato 1992; César 1993). A maioria destes autores relaciona o pico de deposição foliar com a baixa pluviosidade, entretanto, também não constataram correlação significativa entre estes parâmetros. Embora seja freqüente uma relação visual entre as curvas de produção de serapilheira e de precipitação, poucos trabalhos demonstram uma correlação estatística entre elas (Schumacher et al. 2004), provavelmente, em decorrência da irregularidade do regime de chuvas (Oliveira \& Lacerda 1983).

A sazonalidade na serapilheira produzida em florestas tropicais é considerada pequena (Proctor et al. 1983), e segundo Morellato (1992) pode ser inferida pelo valor da razão entre o mês de maior e menor queda de serapilheira. Quando comparados aos de Florestas Estacionais listados por esta autora (1,9 a $5)$, os valores deste índice obtidos neste estudo $(6,6)$ e em outras florestas de restingas $(5,2$ a 9,6) (Britez et al. 2005; Moraes et al. 1998), foram altos, principalmente levando em consideração o clima pouco sazonal da região de sua ocorrência, o que sugere uma forte influência das condições edáficas nos processos que nelas atuam. Variação no grau de sazonalidade de produção entre áreas próximas da Amazônia foi conferida a drenagens distintas do solo (Cuevas \& Medina 1986). Deve ser ponderado, contudo, que a deposição muito baixa, como estimada em julho neste estudo, aumenta sobremaneira este índice, e que o número relativamente baixo de espécies arbóreas da presente fitocenose também pode ter contribuído para uma sazonalidade mais marcante.

Serapilheira acumulada e taxa de decomposição - A serapilheira acumulada confere maior estabilidade ao sistema, e juntamente com o solo, controla vários processos fundamentais na dinâmica dos ecossistemas, como o da produção primária e liberação de nutrientes. Na restinga, onde o solo não constitui uma fonte de nutrientes significativa, a função de reservatório de matéria orgânica e elementos minerais pode ser especialmente importantes (Moraes et al. 1998), agindo também para atenuar os efeitos erosivos da chuva e da radiação solar, intensas no local.

A serapilheira acumulada em florestas tropicais varia em torno de 2,1 a 12,5 t.ha-1, sendo difíceis comparações precisas por depender de diversos fatores, como a produção de serapilheira, qualidade do substrato, declividade do terreno, e pelas diferentes metodologias empregadas (Spain 1984). Do mesmo modo, observa-se uma ampla variação nas taxas de decomposição, a qual Vitousek \& Sanford Jr. (1986) admitem que seja relacionada ao clima e fertilidade do solo. Segundo eles ocorre uma sobreposição dos valores de coeficientes de decomposição entre áreas moderadamente férteis e oxisol/ultisol inférteis, e são menores em áreas de podzol, onde se acumula uma grande camada de serapilheira. Todavia, embora a comunidade estudada apresente uma reduzida taxa de decomposição $\left(\mathrm{k}_{\mathrm{L}}=0,92\right)$, sendo infreqüente valores de $\mathrm{k}$ menores que $1 \mathrm{em}$ florestas tropicais, não se observa um grande acúmulo de serapilheira $\left(5,5\right.$ t.ha $^{-1} \cdot$ ano $\left.^{-1}\right)$ (Tab. 4). Considerando a alta pluviosidade local e o solo muito arenoso, a lenta decomposição, associada tanto às condições edáficas como a natureza do substrato (escleromorfia e baixo níveis de nutrientes), pode, por reduzir a lixiviação (Hay \& Lacerda 1984) e promover um retorno gradual de nutrientes ao solo, ser vantajosa para a comunidade.

Por serem as folhas geralmente consideradas como recurso de melhor qualidade que a fração lenhosa, espera-se que estas apresentem taxa de decomposição mais elevada (Proctor et al. 1992; Mazurec \& Villela 1998; Villela et al. 1998), sendo escassos dados na literatura onde a fração lenhosa apresenta valores superiores (McDonald \& Healey 2000). Neste trabalho, os índices de decomposição foram aproximados entre as duas frações, sugerindo que os ramos $(\leq 5 \mathrm{~cm}$ de diâmetro) participam na ciclagem rápida dos nutrientes entre o solo e as plantas.

Não pode ser observado um padrão sazonal nítido na camada de serapilheira (Fig. 5), embora suas frações, especialmente a foliar que a caracteriza (81\%), tenham sido relacionadas à temperatura (Tab.1; Fig. 6). A ausência de variações mensais significativas neste compartimento condiz com o pressuposto por Olson (1963), de um estado de equilíbrio entre a produção e decomposição, e reflete a sazonalidade coincidente destes processos (Fig. 2 e 7). Ainda que não ocorra uma seca rigorosa, devido à baixa retenção de água do solo, o período de menor pluviosidade pode gerar situações de seca (Britez et al. 2005), reduzindo a produção e decomposição da serapilheira. A decomposição mais acentuada durante a estação chuvosa (Fig. 7), reafirmada pelo estudo da decomposição através da medida direta da perda de peso da serapilheira foliar (L.A. Pires, dados não publicados), é comumente observada em florestas 
tropicais, pois além dos processos físicos (lixiviação), garante condições de umidade favoráveis a atividade de organismos decompositores, bem como do crescimento de raízes e micorrizas que auxiliam neste processo (Luizão \& Schubart 1987).

Os resultados indicam uma interação da sazonalidade da produção e decomposição de serapilheira com fatores climáticos, principalmente temperatura média do período de estudo, e, provavelmente pela proximidade com o oceano, a velocidade do vento. Embora não apresente déficit hídrico acentuado, observa-se uma estação mais quente e úmida, caracterizada por um maior aporte e decomposição de material orgânico no solo, e, possivelmente uma maior absorção de nutrientes. Desta forma, possibilita um incremento na atividade fisiológica das plantas, que alocam estes recursos para suas atividades vegetativa e reprodutiva, antes de sua perda por lixiviação. As características do solo, altamente lixiviável e com baixa fertilidade, parecem também exercer forte influência na determinação destes processos. A produção e decomposição relativamente baixas, o padrão sazonal, bem como o caráter perenifólio da maioria das espécies, escleromorfia, e uma rede de raízes superficiais, denotam adaptações da comunidade vegetal que permitem uma eficiente ciclagem de nutrientes mesmo sob às condições ambientais adversas em que se encontra, e, conseqüentemente, indicam sua fragilidade frente a perturbações antrópicas que alterem estes mecanismos.

\section{Agradecimentos}

Ao Conselho Nacional de Desenvolvimento Científico e Tecnológico (CNPq), pela bolsa concedida a primeira autora; a Daniela G. Simão e Denise M. Braz, pelo abstract; ao Dr. Cleber I. Salimon, Dr. Marcelo T. Nascimento e assessores da Revista Acta Botanica Brasilica, pelas sugestões no manuscrito.

\section{Referências bibliográficas}

Araújo, D.S.D. 1992. Vegetation types of sandy coastal plains of tropical Brazil: a first aproximation. In: U. Seeliger (coord.). Coastal plant communities of Latin America. New York, Academic Press.

Bigarella, J.J. 1965. Nota explicativa acompanhando a folha geológica de Paranaguá. Universidade Federal do Paraná. Boletim da Universidade Federal do Paraná, Geologia 13: 1-6.
Bray, J.R. \& Gorham, E. 1964. Litter production in forests of the word. Advances in Ecological Research 2: 101-157.

Britez, R.M.; Pires, L.A.; Reissmann, C.B.; Pagano, S.N.; Silva, S.M.; Athayde, S.F. \& Lima, R.X. 2005 Ciclagem de nutrientes na planície costeira. Pp. 145-168. In: M.C.M. Marques \& R.M. Britez (orgs.). História Natural e Conservação da Ilha do Mel. Curitiba, Editora da Universidade Federal do Paraná.

Britez, R.M.; Reissman, C.B.; Silva, S.M. \& Santos Filho, A. 1992. Deposição estacional de serapilheira e macronutrientes em uma floresta de Araucária, São Mateus do Sul, Paraná. Revista do Instituto Florestal 4(3): 766-772.

Britez, R.M.; Santos Filho, A.; Reissman C.B.; Silva S.M.; Athayde, S.F.; Lima, R.X. \& Quadros, R.M.B. 1997. Nutrientes no solo de duas florestas da planície litorânea da Ilha do Mel, Paranaguá, PR. Revista Brasileira de Ciência do Solo 21: 625-34.

Campos, H. 1993. Estatística experimental não-paramétrica. 4 ed., Piracicaba, ESALQ.

César, O. 1993. Produção de serapilheira na mata mesófila semidecídua da fazenda Barreiro Rico, município de Anhembi, SP. Revista Brasileira de Biologia 53(4): 671-681.

Cuevas, E. \& Medina, E. 1986. Nutrient dynamics within Amazonian forests. I. Nutrient flux in fine litter fall and efficiency of nutrient utilization. Oecologia 68: 466-472.

Diniz, S. \& Pagano, S.N. 1997. Dinâmica de folhedo em Floresta Mesófila Semidecídua no município de Araras, SP. I - Produção, decomposição e acúmulo. Revista do Instituto Florestal 9(1): 27-36.

Embrapa. 1999. Sistema Brasileiro de Classificação de Solos. Empresa Brasileira de Pesquisa Agropecuária. Rio de Janeiro, Centro Nacional de Pesquisa de Solos.

Golley, F.B. 1978. Ciclagem de minerais em um ecossistema de floresta tropical úmida. São Paulo, EPU: EDUSP.

Hay, J.D. \& Lacerda, L.D. 1984. Ciclagem de nutrientes no ecossistema de restinga. In: L.D. Lacerda et al. (org.). Restingas: origem, estrutura e processos. Niterói, CEUFF.

Hopkins, B. 1966. Vegetation of the Olkemeji Forest Reserve, Nigéria. IV: The litter and soil with special reference to their seasonal changes. Journal of Ecology 54: 687-703.

Iapar - Instituto Agronômico do Paraná. 1978. Cartas climáticas básicas do Estado do Paraná. Londrina, Iapar.

Jackson, J.F. 1978. Seasonnality of flowering and leaf-fall in a Brazilian subtropical lower montane moist forest. Biotropica 10(1): 38-42.

Janzen, D.H. 1980. Ecologia vegetal nos trópicos. São Paulo, EPU: EDUSP.

Klinge, H. 1977. Fine litter production and nutrient return to the soil in three natural forest stands of eastern Amazonia. Geo-Eco-Trop 1: 415-22.

König, F.G.; Schumacher, M.V.; Brun, E.J. \& Seling, I. 2002. Avaliação da sazonalidade da produção de serapilheira numa floresta estacional decidual no município de Santa Maria-RS. Revista Árvore 26(4): 429-435. 
Leitão Filho, H.F.; Pagano, S.N.; César, O.; Timoni, J.L. \& Rueda, J.J. 1993. Aspectos da ciclagem de nutrientes. Pp. 129-163. In: H.F. Leitão Filho (org.). Ecologia da mata Atlântica em Cubatão. São Paulo, Editora da Universidade Estadual Paulista/ Editora da Universidade de Campinas.

Londsdale, W.M. 1988. Predicting the amout of litterfall in forests of the world. Annals of Botany 61:319-324.

Luizão, F.J. \& Schubart, H.O.R. 1987. Litter production and decomposition in Terra Firme forest of Central Amazonia. Experientia 43: 259-265.

Maack, R. 1981. Geografia Física do Estado do Paraná. 2a ed. Rio de Janeiro, José Olympio.

Malaisse, F.; Freson, R.; Goffinet, G. \& Malaisse-Mousset, M. 1975. Litter fall and litter breakdown in Mionbo. Pp. 137-152. In: F.B. Golley \& E. Medina (eds.). Tropical ecological systems - Trends in terrestrial and aquatic research 11 . Berlin.

Mazurec, A.P. \& Villela, D.M. 1998. Produção e camada de serapilheira em uma Mata Atlântica na Serra do Imbé, norte fluminense, em diferentes altitudes. Pp. 36-42. In: Anais do IV Simpósio de Ecossistemas Brasileiros. v.3., Águas de Lindóia, São Paulo, ACIESP.

McDonald, M.A. \& Healey, J.R. 2000. Nutrient cycling in secondary forest in the Blue Mountains of Jamaica. Forest Ecology and Management 139: 257-278.

Meentemeyer, V.; Box, E.O. \& Thompson, R. 1982. World patterns and amounts of terrestrial plant litter production. BioScience 32(2): 125-128.

Moraes, R.M. \& Domingos, M. 1997. Elementos minerais em folhas de espécies arbóreas de Mata Atlântica e Mata de restinga, na Ilha do Cardoso, SP. Revista Brasileira de Botânica 20: 133-138.

Moraes, R.M.; Delitti, W.B.C.; Rinaldi, M.C.S. \& Rebelo, C.F. 1998. Ciclagem mineral em Mata Atlântica de encosta e Mata sobre restinga: nutrientes na serapilheira acumulada. Pp. 71-77. In: Anais do IV Simpósio de Ecossistemas Brasileiros. v. 2., Águas de Lindóia, São Paulo, ACIESP.

Moraes, R.M.; Delitti, W.B.C. \& Struffaldi-De-Vuono, Y. 1999. Litterfall and litter nutrient content two Brazilian Tropical Forests. Revista Brasileira de Botânica 22(1): 9-16.

Morellato, L.P.C. 1992. Nutrient cycling in two south-east Brazilian forests. I. Litterfall and litter standing crop. Journal of Tropical Ecology 8(2): 205-215.

Oliveira, R.R. \& Lacerda, L.D. 1993. Produção e composição química da serapilheira na Floresta da Tijuca, RJ. Revista Brasileira de Botânica 16(1): 93-99.

Olson, J.S. 1963. Energy storage and the balance of producers and decomposers in ecological systems. Ecology 44: 223-331.

Pagano, S.N. 1989. Produção de folhedo em mata mesófila semidecídua no município de Rio Claro, SP. Revista Brasileira de Biologia 49(3): 633-639.

Peres, J.R.R.; Suhet, A.R.; Vargas, M.A.T. \& Droxdowicz, A. 1983. Litter production in areas of Brazilian “cerrados". Pesquisa Agropecuária Brasileira 18(9): 1037-1043.
Proctor, J.; Anderson, J.M.; Fogden, S.C.L. \& Vallack, H.W. 1983. Ecological studies in four contrasting lowland rain forests in Gunung Mulu National Park, Sarawak. II. Litterfall, litter standing crop and preliminary observations on herbivory. Journal of Ecology 71(1): 261-283.

Ramos, M.C.L. \& Pellens, R. 1993. Produção de serapilheira em ecossistema da restinga de Maricá, Estado do Rio de Janeiro. Pp. 89-98. In: Anais do III Simpósio de Ecossistemas da Costa Brasileira. v. 3, Serra Negra, São Paulo, ACIESP.

Schlittler, F. H.M.; De Marinis, G. \& César, O. 1993. Produção de serapilheira na Floresta do Morro do Diabo, Pontal do Paranapanema - SP. Naturalia 18: 135-147.

Schumacker, M.V.; Brun, E.J.; Hernandes, J.I. \& König, F.G. 2004. Produção de serapilheira em uma floresta de Araucaria angustifólia (Bertol.) Kuntze no município de Pinhal Grande-RS. Revista Árvore 28(1): 29-37.

Scott, D.A.; Proctor, J. \& Thompson, J. 1992. Ecological studies on a lowland evergreen rain forest on Maracá Island, Roraima, Brazil. II. Litterfall and nutrient cycling. Journal of Ecology 80: 689-703.

Silva, S.M. \& Britez, R.M. 2005. A vegetação da planície costeira. Pp. 49-84. In: M.C.M. Marques \& R.M. Britez (orgs.). História Natural e Conservação da Ilha do Mel. Curitiba, Editora da Universidade Federal do Paraná.

Smith, K.; Gholz, H.L. \& Oliveira, F.A. 1998. Litterfall and nitrogen-use efficiency of plantations and primary forest in the eastern Brazilian Amazon. Forest Ecology and Management 109: 209-220.

Spain, A.V. 1984. Litterfall and the standing crop of litter in three tropical Australian rainforests. Journal of Ecology 72(3): 947-961.

Staelens, J.; Nachtergale, L.; Luyssaert, S. \& Lust, N. 2003. A model of wind-influenced leaf litterfall in a mixed hardwood forest. Canadian Journal of Forest Research 33(2): 201-209.

Sundarapadian, S.M. \& Swamy, P.S. 1999. Litter production and leaf-litter decomposition of selected tree species in tropical forests at Kodayar in the Western Ghats, India. Forest Ecology and Management 123: 231-244.

Tanner, E.V.J. 1980. Litterfall in montane rain forests of Jamaica and its relation to climate. Journal of Ecology 68: $833-848$.

Varjabedian, R. \& Pagano, S.N. 1989. Produção e decomposição de folhedo em um trecho de Mata Atlântica de encosta no Município do Guarujá, SP.Acta Botanica Brasilica 1(2) (supl.): 243-256.

Villela, D.M.; Buffon, L.B.; Aragão, L.E.O.E.C.; Gama, D.M.; Nascimento, M.T. \& Rezende, C.E. 1998. Effect of selective logging on litter production and decomposition in Atlantic Forest, RJ, Brazil. In: Anais do IV Simpósio de Ecossistemas Brasileiros. v.4., Águas de Lindóia, São Paulo, ACIESP.

Villela, D.M. \& Proctor, J. 1999. Litterfall mass and chemistry and nutrient retranslocation in a monodominant forest on Maracá Island, Roraima, Brazil. Biotropica 31(2): 198-211.

Vitousek, P.M. 1982. Nutrient cycling and nutrient use efficiency. The American Naturalist 119(4): 53-72. 
Vitousek, P.M. 1984. Litterfall, nutrient cycling and nutrient limitation in tropical forests. Ecology 65(1): 285-298.

Vitousek, P.M. \& Sanford Jr., R.L. 1986. Nutrient cycling in moist tropical forest. Annual Review of Ecology and Systematics 17: 137-167.

Vogt, K.A.; Grier, C.C. \& Vogt, D.C. 1986. Production, turnover and nutrient dynamics of above and bellowgroud detritus of word forest. Advances in Ecological Research 15: 303-77.
Werneck, M.S.; Pedralli, G. \& Gieseke, L.F. 2001. Produção de serapilheira em três trechos de uma floresta semidecídua com diferentes graus de perturbação na Estação Ecológica do Tripuí, Ouro Preto, MG. Revista Brasileira de Botânica 24(2): 195-198.

Williams-Linera, G. \& Tolome, J. 1996. Litterfall, Temperate and Tropical Dominant Trees, and Climate in a Mexican Lower Montane Forest. Biotropica 28(4b): 649-656. 